\title{
Índigo Karmin İle Spektrofotometrik Nitrat Tayini
}

Spectrophotometric Nitrate Determination with Indigo Carmine

\section{ÖZET}

Geliştirilen spektrofotometrik yöntemle 0,0-1,0 ppm nitrat azotu $\left(=\mathrm{NO}_{3}-\mathrm{N}^{\prime} \mathrm{u}\right)$ aralı $\breve{g}_{1}$ nda nitrat tayini yapılabilir. Tayinin hassasiyeti 0,018 ppm'dir.

Deney sonuçları zaman, sıcaklık, sülfürik asit konsantrasyonu gibi reaksiyon şartlarına bağlı olduğundan bu faktörler deney süresince sabit tutulmalıdır ve her numune serisi için yeni bir kalibrasyon eğrisi çizilmelidir.

\section{S U M M A R Y}

The spectrophotometric method developed make it possible to determine nitrate in the concentration range of $0,0-1,0$ ppm nitratenitrogen $(=\mathrm{NO} 3-\mathrm{N})$. The sensitivity of the determination is 0,018 ppm.

The results of the experiments depend strictly on the reaction conditions such as time, temperature and sulphuric acid concentration. Therefore they must be held constant during the experiments. And for each series of samples a new calibration curve must be drawn.

Anahtar Kelimeler: Nitrat tayini, İndigo Karmin, Spektrofotometri

Nitrat, N-siklusunda biyolojik oksidasyonun son ürünü olarak meydana gelir. Sularda bulunan nitrat; bitkisel ve hayvansal kaynak11 proteinlerin bakteriyel bozunması, azot içeren fabrika artık suları, azotlu sunî gübrelerin kullanılması, atmosferde bulunan azot oksitlerin suda çözünmesi gibi değişik kaynaklardan ileri gelir ve normal miktarı 5-10 ppm'i geçmez.

Redaksiyona verildiği tarih: 29.1.1987

* Sınai Kimya Anabilim Dalı, Fen Fakültesi, Ankara Üniversitesi

** Analitik Kimya Anabilim Dalı, Eczacılık Fakültesi, Ankara Üniversitesi 
Nüfus yoğunluğunun artması ve sanayileşme nitrat oluşumunu artırdı̆̆ından bugün kirlenmiş sularda 200 ppm'i aşan miktarlarda nitrata rastlanmaktadir.

Yüksek oranda nitrat içeren sular, yetişkinler tarafından sürekli içildiğinde-nitratın sindirim sisteminde bakterilerin etkisiyle nitrite, nitritin de kanserojen etkili nitrozamine dönüşebilmesi dolayısıylakansere sebep olabilmektedir(1).

Bu sular anne sütünün seyreltilmesinde kullanılmaları halinde ise bebeklerde Siyanoz'a sebep olmakta ve birçok vaka ölümle sonuçlanmaktadır. Dünya Sağlık Teşkilatı (WHO), sularda bulunabilecek nitrat konsantrasyonu üst sınırını $50 \mathrm{ppm}$ olarak saptamıştır (2). Bu nedenlerle sularda nitrat tayini günümüzde önem kazanmıştır.

Nitrat tayininde kullanılacak yöntemin 1) hızlı, 2) spesifik, 3) hassas ve 4) güvenilir olması istenir. Bugün nitrat tayini için en çok fenolik yapının nitrolanmasına dayanan "Fenoldisülfonik Asit Metodu" $(3,4,5)$ ve reaktifin oksidasyonuna dayanan "Brucin Metodu" $(3,4,6,7)$ kullanılmaktadır. 1. metodun dezavantajı çok zaman almasıdır. 2. metod ise 1. si kadar hassas değildir.

$\mathrm{Bu}$ çalışmada nitratın İndigo Karmin reaktifiyle çabuk ve hassas olarak tayin edilip edilemeyeceği araştırıldı. Reaktif bir spektrofotometrik çalışma (8) dişında nitratın titrimetrik olarak tayininde kullanılmıştır $(9,10,11,12,13)$. Spektrofotometrik yöntemle yapılan ön denemeler sonuç vermediğinden tayin için optimum şartlar araştirildi.

DENEL KISIM

\section{Materyal}

\section{Kullanılan Cihazlar}

1) UV-Vis Spektrofotometre

2) Termostatli $\mathrm{Su}$ Banyosu

: Pye Unicam SP 8-100

: Grant Instruments

Ltd., Type SB 2

3) Etüv( $+1{ }^{\circ} \mathrm{C}$ duyarlıkla çalışmaktadır $)$ : Hereaus, Typ KT 500

4) $\mathrm{pH}$ metre

5) Magnetik Karıştırıcı

: Tacussel TS $70 \mathrm{~N}-1$

: Elektro-Mag, Type MS 


\section{Kullanılan Çözelti ve Reaktifler}

1) Stok Nitrat Çözeltisi: $105^{\circ} \mathrm{C}$ de sabit tartıma getirilmiş $0,7218 \mathrm{~g}$ potasyum nitrat (Merck) distile suyla çözülerek $1000 \mathrm{ml}$ ye tamamlanır. (1 ml stok nitrat çözeltisi $=0,1 \mathrm{mg} \mathrm{NO} 3-\mathrm{N}^{\prime} \mathrm{u}$ (= nitrat azotu))

2) İndigo Karmin Çözeltisi: $105^{\circ} \mathrm{C}$ de sabit tartıma getirilmiş 0,2500 g İndigo Karmin (BDH) distile suyla çözülerek $250 \mathrm{ml}$ ye tamamlanır. Çözelti takriben 0,002 M'dür $(0,0005$ M ve 0,001 M çözeltiler de - gerekli miktar madde kullanılarak-aynı şekilde hazırlanırlar).

3) İndigo Karmin-Sülfürik Asit Çözeltisi: 5 hacım İndigo Karmin Çözeltisi 18 hacim derişik sülfürik asitle (BDH) karıştırılarak ha-

zırlanır. İşlem buz banyosu içinde yapılarak karışım sıcaklığının $35^{\circ} \mathrm{C}$ üzerine çıkmaması sağlanır. Çözelti buzdolabında muhafaza edilir.

Çalışmada kullanılan bütün reaktifler analitik saflıktadır. Çözeltiler bidistile su ile hazırlanmışlardır.

\section{Yöntem}

\section{Ön Denemeler}

Literatür yöntemiyle (8) kalibrasyon eğrisi çizilmeye çalışıldı (Tablo 1). İndigo Karmin'in (İK) nitratla reaksiyonuna asit konsantrasyonunun etkisini incelemek amacıyla 9,0-10,6 M sülfürik asit içeren ortamlarda tayin yapıld 1 (Tablo 2).

Reaksiyonun oda sıcaklığında yürüyüp yürümediğini incelemek için su banyosunda 1sıtılmayan reaksiyon karışımı ile kaynar su banyosunda $\left(95^{\circ} \mathrm{C}\right)$ 1sıtılan karışımın verdiği absorbanslar karşılaştırıldı ( Tablo 3).

Reaktif konsantrasyonunun deneydeki rolünü incelemek için 0,001 M ve 0,002 M İK çözeltileriyle tayin yapıldı (Şekil 1).

Suyun kaynama sıcaklığı deniz seviyesinden yüksekliğe bağlı olarak değiştiğinden (Ankara'da $95^{\circ} \mathrm{C}$ ) bu deneyden itibaren 1sıtma işlemi $100^{\circ} \mathrm{C}$ sıcaklıktaki yağ banyosunda yapıldı ve 0,002 M İK çözeltisi kullanıldı. 
Tablo 1: Literatür yöntemiyle $0,0-2,0 \mathrm{ppm}$ ve $0,0-8,0 \mathrm{ppm} \mathrm{NO}-\mathrm{N}^{\prime}$ u için okunan absorbans değerleri

\begin{tabular}{|c|c|c|c|c|c|c|}
\hline \multirow{2}{*}{$\begin{array}{c}\mathrm{NO}_{3}-\mathrm{N} \\
(\mathrm{ppm})\end{array}$} & \multicolumn{4}{|c|}{ A $\quad$ B $S$ O $R$ B A $N$ S } & \multirow{2}{*}{$\begin{array}{l}\mathrm{NO}_{3}-\mathrm{N} \\
(\mathrm{ppm})\end{array}$} & \multirow[t]{2}{*}{ ABS. } \\
\hline & Lit. Veril. & 1. Gün & 2. gün & 3. Gün & & \\
\hline 0.0 & 0.500 & 0.500 & 0.496 & 0.470 & 0.0 & 1.930 \\
\hline 0.1 & - & 0.281 & 0.360 & 0.277 & 1.0 & 0.358 \\
\hline 0.2 & - & 0.175 & 0.417 & 0.181 & 2.0 & 0.0 \\
\hline 0.3 & - & 0.083 & 0.410 & 0.336 & 4.0 & 0.0 \\
\hline 0.4 & - & 0.251 & 0.392 & 0.090 & 6.0 & 0.0 \\
\hline 0.5 & 0.305 & 0.124 & 0.313 & 0.057 & 8.0 & 0.0 \\
\hline 1.0 & - & 0.014 & 0.0 & 0.0 & & \\
\hline 1.5 & - & 0.0 & 0.0 & 0.0 & & \\
\hline 2.0 & _ & 0.0 & 0.0 & 0.0 & & \\
\hline
\end{tabular}

Tablo 2: Sülfürik asit konsantrasyonunun reaksiyona etkisi

\begin{tabular}{|c|c|c|c|}
\hline (Numuneler $0,5 \mathrm{ppm}$ & $\mathrm{N}_{3}-\mathrm{N}^{\prime} \mathrm{u}$ & içerir) \\
\hline $\mathrm{H}_{2} \mathrm{SO}_{4}$ & A B S O R B A N S \\
\hline Konst.u & Num.No. 1 & 2 & 3 \\
\hline 9.0 & 0.054 & 0.241 & \\
\hline 9.2 & 0.041 & 0.089 & - \\
\hline 9.4 & 0.249 & 0.033 & - \\
\hline 9.6 & 0.045 & 0.017 & 0.100 \\
\hline 9.8 & 0.209 & 0.051 & - \\
\hline 10.0 & 0.291 & 0.005 & 0.054 \\
\hline 10.2 & 0.224 & 0.195 & 0.130 \\
\hline 10.4 & 0.049 & 0.021 & 0.034 \\
\hline 10.6 & 0.047 & 0.082 & - \\
\hline
\end{tabular}


Deneyde 10 dakikalık 1sıtma işlemi dışında, ortama sülfürik asit ilave edildiğinde ve numune çözeltilerinin balonjojeye aktarmak için suyla seyreltilmesi esnasında da -suyla sülfürik asitin karışması dolayısıyla -sıcaklık yükselmektedir. Bu sıcaklık yükselmesinin deneye etkisini incelemek için bir seri numune yukarıda belirtilen üç deney basamă̆ından sonra buzlu su banyosunda oda sicaklığına soğutuldu ( Tablo 4).

Isıtma süresi ve 1sıtma sıcaklığının reaksiyona etkisini incelemek için numune serileri $100^{\circ} \mathrm{C}$ de 10 dakika, $105^{\circ} \mathrm{C}$ de 10 dakika, $100^{\circ} \mathrm{C}$ de 15 dakika ve $100^{\circ} \mathrm{C}$ de 5 dakika isitildilar (Tablo 5).

Tablo 3. İndigo Karmin'in nitratla reaksiyonuna sıcaklığın etkisi $(0,0005 \mathrm{M}$ İK ile $)$

\begin{tabular}{|c|c|c|c|c|c|c|c|c|}
\hline \multirow{2}{*}{$\begin{array}{r}\mathrm{N} 03-\mathrm{N} \\
(\mathrm{ppm})\end{array}$} & \multirow{2}{*}{ Sicaklık } & \multicolumn{7}{|c|}{ A B S O R B A N S } \\
\hline & & 1 & 2 & 3 & 4 & 5 & 6 & 7 \\
\hline 0 & \multirow[t]{2}{*}{$20^{\circ}$} & 0.523 & 0.521 & - & \multirow{2}{*}{$\begin{array}{l}0.496 \\
0.412\end{array}$} & 0.496 & 0.528 & 0.529 \\
\hline 0.5 & & 0.375 & 0.510 & - & & 0.473 & 0.501 & 0.397 \\
\hline 0.0 & \multirow{2}{*}{$95^{\circ} \times 10^{\prime}$} & 0.519 & 0.523 & & 0.496 & 0.495 & 0.528 & 0.528 \\
\hline 0.5 & & 0.300 & 0.026 & - & 0.224 & 0.195 & 0.011 & 0.013 \\
\hline 0.5 & $95^{0} \times 5^{\prime}$ & 0.078 & 0.112 & 0.013 & 0.022 & 0.067 & 0.050 & 0.016 \\
\hline
\end{tabular}

Tablo 4. Soğutma işleminin reaksiyona etkisi $\left(0.002 \mathrm{M} \dot{\mathrm{IK}}+1.0 \mathrm{ppm} \mathrm{NO}_{3}-\mathrm{N}^{\prime} \mathrm{u}\right)$

\begin{tabular}{|c|c|c|}
\hline \multirow{2}{*}{$\begin{array}{c}\text { Seri } \\
\text { no. }\end{array}$} & A B S O R B A N S \\
\cline { 2 - 4 } & Normal & Soğutulan \\
\hline 1 & $0.515 \pm 0.013$ & $0.595 \pm 0.007$ \\
\hline 2 & $0.538 \pm 0.007$ & $0.610 \pm 0.011$ \\
\cline { 2 - 4 } 3 & $0.551 \pm 0.007$ & $0.632 \pm 0.007$ \\
\hline
\end{tabular}

Ortama ilave edilen sodyum klorürün katalizör etkisini (8) incelemek için sodyum klorür içermeyen ve $0,1 \mathrm{ml} \% 5, \quad \% \quad 10, \%$ 20'lik sodyum klorür içeren ortamlarda deney yapıldı (Tablo 6).

$100^{\circ} \mathrm{C}$ de 1 șıtma işleminden önce reaksiyon karışımını bekletmenin rolünü incelemek için bir seri numune bekletmeden, diğer iki seri ise 2 ve 5 dakika bekletildikten sonra $100^{\circ} \mathrm{C}$ de isitildilar (Tablo 6). 


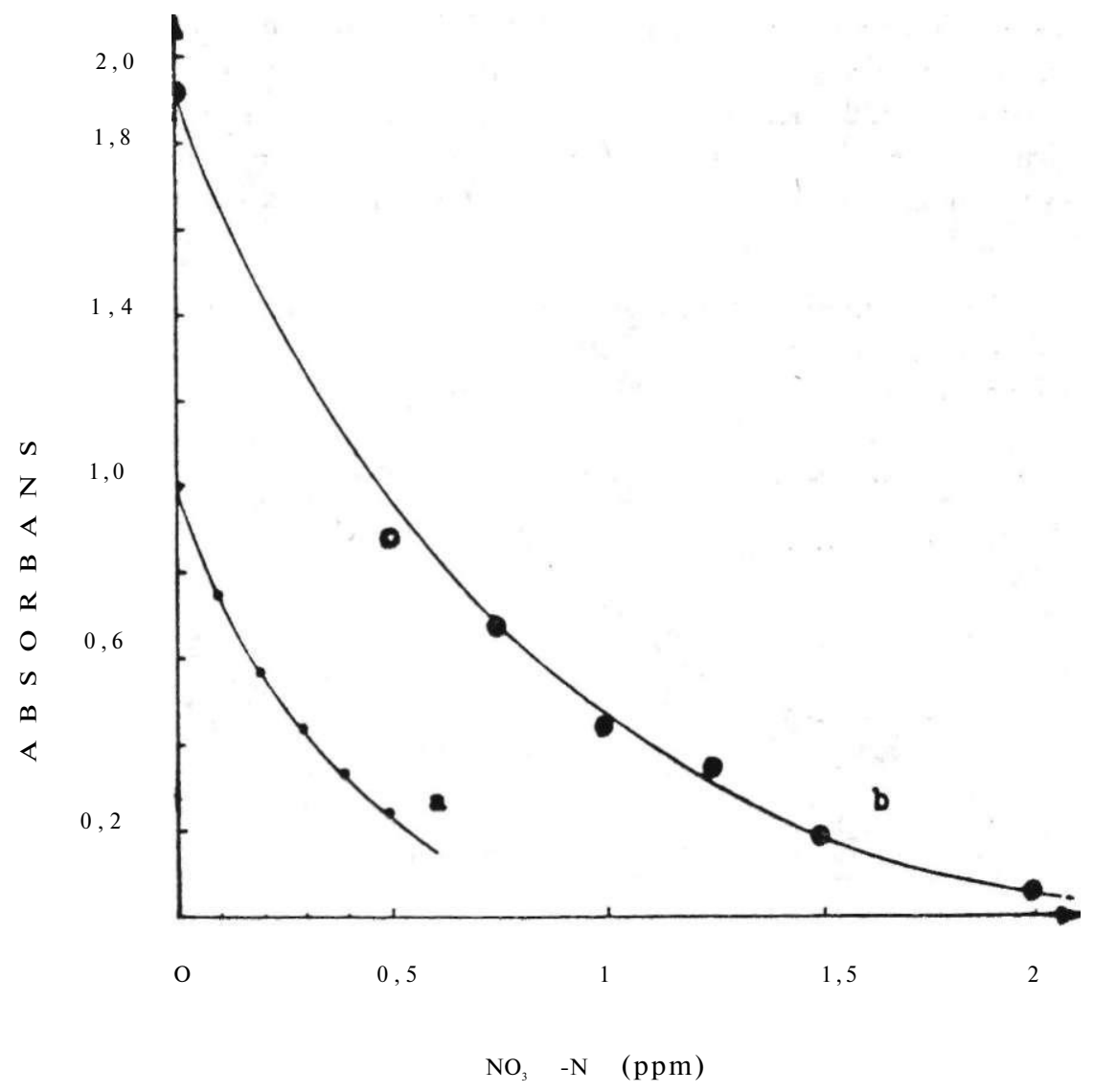

Şekil 1. a) 0,001 M İK, b) 0,002 M İK çözeltisiyle çizilen kalibrasyon eğrileri.

Reaktif çözeltisi, İK çözeltisi sülfürik asitle karıştırılarak hazırland1 (Sayfa 36, No: 3).

Sıcaklık değişkeni kontrol altına alındıktan ve reaktif hazırlama yöntemi değiştirildikten sonra sodyum klorür içermeyen numunelerde sonuçlar tekrar incelendi. Sodyum klorürsüz ortamda absorbanslar yüksek çıkacağından çözeltiler (1:1) oranında seyreltildikten sonra ölçüm yapıldı (Tablo 7).

Islah edilen şartlarda 0,002 M İK içeren reaktif çözeltisiyle çok yüksek absorbans değerleri elde edilmesi numunelerin (1:1) oranında 
Tablo 5. Isıtma süresi ve sıcaklığın reaksiyona etkisi $(0,002 \mathrm{M}$ İK ile)

\begin{tabular}{|c|c|c|c|c|}
\hline Seri no & $\mathrm{N}_{3}-\mathrm{N}(\mathrm{ppm})$ & Banyo sicaklığ 1 & \multicolumn{2}{|c|}{ Banyoda kal- } \\
ma süresi & \multicolumn{2}{|c|}{ A S O R B N S } \\
\hline 1 & 1.0 & 1000 & $10^{\prime}$ & $0.698 \pm 0.008$ \\
\hline 2 & 1.0 & 1000 & $5^{\prime}$ & $0.884 \pm 0.057$ \\
\hline 3 & 1.0 & 1000 & $15^{\prime}$ & $0.707 \pm 0.014$ \\
\hline 4 & 1.0 & 1000 & $15^{\prime}$ & $0.715 \pm 0.002$ \\
\hline 5 & 1.0 & $105^{\circ}$ & $10^{\prime}$ & $0.734 \pm 0.009$ \\
\hline 6 & 1.0 & 1050 & $10^{\prime}$ & $0.728 \pm 0.011$ \\
\hline
\end{tabular}

Tablo 6. a) Ortamdaki sodyum klorür miktarının, b) numuneleri isıtmadan önce bekletmenin reaksiyona etkisi $(0,002 \mathrm{M}$ İK ile $)$

\begin{tabular}{|c|c|c|c|c|c|c|}
\hline & \multicolumn{4}{|c|}{ A B S O R B A N S } \\
\hline & & & & 1 & 2 & 3 \\
\hline $\begin{array}{l}\text { Seri } \\
\text { no. }\end{array}$ & $\begin{array}{l}\mathrm{NO}_{3}-\mathrm{N} \\
(\mathrm{ppm})\end{array}$ & $\begin{array}{c}\text { İlave olunan } \\
\mathrm{NaCl}\end{array}$ & \multicolumn{2}{|c|}{ Bekletilmedi } & $\begin{array}{l}2 \text { dakika } \\
\text { Bekletildi }\end{array}$ & $\begin{array}{l}5 \text { dakika } \\
\text { Bekletildi }\end{array}$ \\
\hline 1 & 0.5 & & & - & $1.408 \pm 0.07$ & \\
\hline 2 & 1.0 & & & - & $0.949 \pm 0.00$ & - \\
\hline 3 & 0.5 & \multirow{2}{*}{$0.1 \mathrm{ml} \times 5$} & & - & $0.959 \pm 0.01$ & \\
\hline 4 & 1.0 & & 1.178 & \pm 0.186 & $0.493 \pm 0.03$ & $0.503 \pm 0.056$ \\
\hline 5 & 0.5 & \multirow{2}{*}{$0.1 \mathrm{ml} \mathrm{x} \% 10$} & \multicolumn{2}{|c|}{-} & $0.947 \pm 0.01$ & - \\
\hline 6 & 1.0 & & 1.346 & \pm 0.210 & $0.505 \pm 0.01$ & $0.499 \pm 0.028$ \\
\hline 7 & 0.5 & \multirow{2}{*}{$0.1 \mathrm{ml} \mathrm{x} \% 20$} & \multicolumn{2}{|c|}{-} & $0.916 \pm 0.01$ & \\
\hline 8 & 1.0 & & \multicolumn{2}{|c|}{-} & $0.514 \pm 0.01$ & $0.661 \pm 0.255$ \\
\hline
\end{tabular}

Tablo 7. Sodyum klorür içermeyen numunelerde tekrar edilebilirlik (Önerilen 0,002 M İK ile) "Numuneler (1:1) oranında seyreltilmiştir.

\begin{tabular}{|c|c|c|c|}
\hline $\mathrm{NO}_{3}-\mathrm{N}$ & \multicolumn{3}{|c|}{$\mathrm{A}$ B S O R B A N S } \\
\hline$(\mathrm{ppm})$ & Reaktif 1 & 2 & 3 \\
\hline 1.0 & $0.561 \pm 0.000$ & 0.560 & $0.555 \pm 0.006$ \\
\cline { 1 - 3 } 1.0 & $0.562 \pm 0.001$ & $0.5600 \pm 0.001$ & 0.573 \\
\hline 1.0 & $0.558 \pm 0.004$ & $0.560 \pm 0.001$ & $0.570 \pm 0.002$ \\
\hline 1.0 & $0.560 \pm 0.006$ & $0.568 \pm 0.003$ & $0.578 \pm 0.002$ \\
\hline 1.0 & $0.560 \pm 0.000$ & $0.576 \pm 0.004$ & - \\
\hline
\end{tabular}


seyreltilmesini gerektireceğinden $0,0-1,0$ ppm $\mathrm{NO}_{3}-\mathrm{N}^{\prime} \mathrm{u}$ içeren standart çözeltilerle 0,001 M İK çözeltisinin verdiği sonuçlar incelendi (Şekil 2).

0,0-1,0 ppm $\mathrm{NO}_{3}-\mathrm{N}^{\prime} \mathrm{u}$ içeren standart çözeltilerden yararlanılarak fenoldisülfonik asit reaktifiyle (FdS.a.) kalibrasyon eğrisi çizildi (Şekil 3).

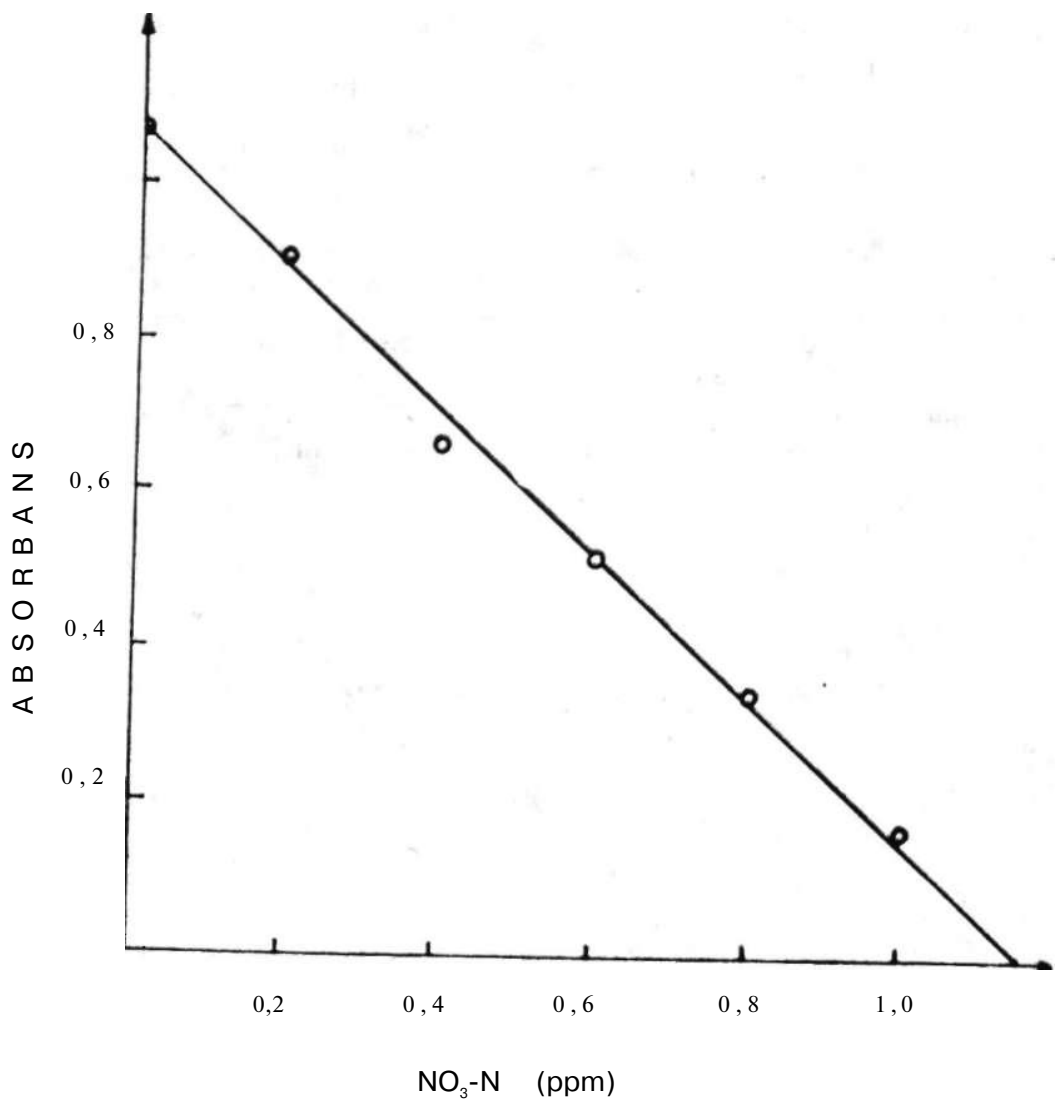

Şekil 2. 0,001 M İK içeren reaktif çözeltisiyle çizilen kalibrasyon eğrisi.

Geliştirilen yöntemde sülfürik asit konsantrasyonunun reaksiyon yürüyüşüne etkisini incelemek amacıyla 8,0-13,0 M sülfürik asit içeren ortamlarda tayin yapıldı (Şekil 4).

Ölçüm çözeltisinin renginin bozunma hızını incelemek amacıyla çözeltinin absorbansı hazırlandıktan 1/2, 1, 1.5, 2, 3, 4 ve 5 saat sonra ölçüldü (Şekil 5). 


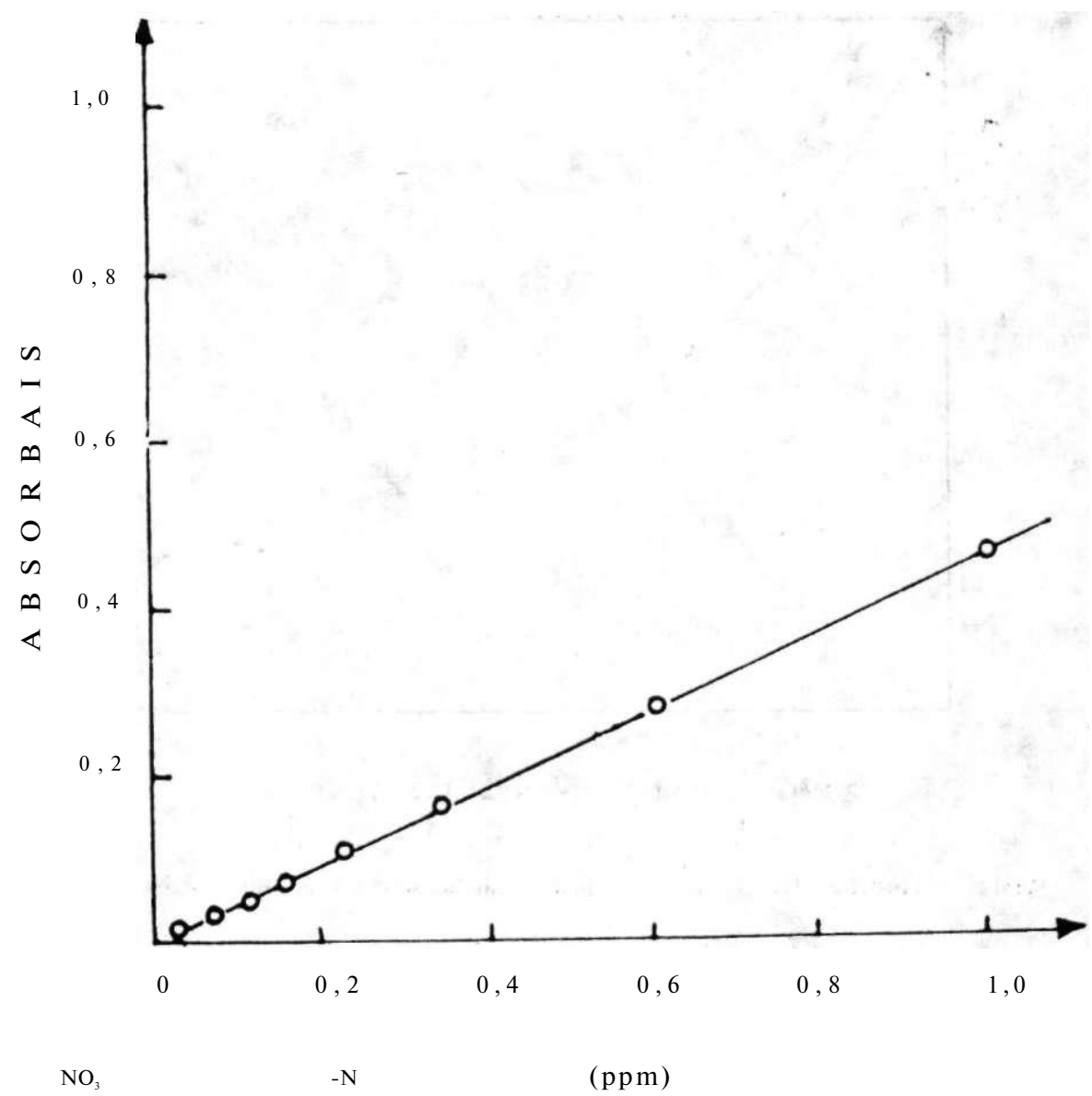

Şekil 3. Fenoldisülfonik asit reaktifiyle çizilen kalibrasyon eğrisi.

Hazırlanan reaktif çözeltisinin dayanıklılığ 2 ay süreyle incelendi. Sonuçlar literatür yöntemiyle (8) hazırlanan reaktif çözeltisinin dayanıklılığımla karşılaştırıldı (Tablo 8).

Suda en çok rastlanan klorür, nitrit, sülfat, fosfat, amonyum, magnezyum, kalsiyum, demir (II), demir (III) iyonları ve organik maddelerin 1000 ppm'e kadar konsantrasyonlarda İK ve FdS. a. yöntemine bozucu etkileri incelendi (Tablo 9).

Klorür iyonunun katı gümüş sülfatın aşırısıyla çöktürülerek uzaklaştırılmasının çözeltinin absorpsiyonuna etkisi incelendi. 
Aral OLCAY, Cem YÜCESOY

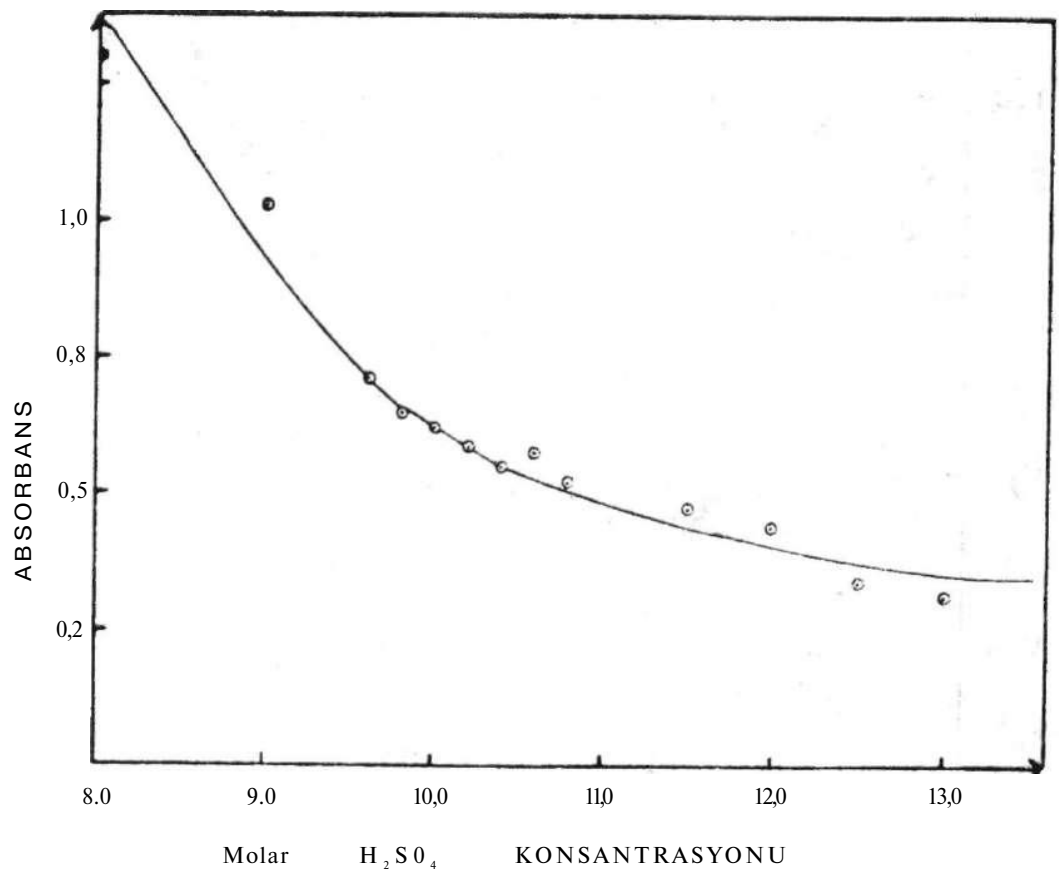

Şekil 4. Geliştirilen İK yönteminde sülfürik asit konsantrasyonunun reaksiyona etkisi.

Tablo8. a) Önerilen reaktif çözeltisinin (0,001 M İK içerir), b) Literatürdeki reaktif çözeltisinin $\left(0,0005\right.$ M İK) dayanıklılığı. ( ${ }^{x} \mathrm{Gün}$ cinsinden reaktif tazeliği)

\begin{tabular}{|c|c|c|}
\hline $\mathrm{Gün}^{\times}$ & Absorbans & $\begin{array}{c}\% \\
\text { Bozunma }\end{array}$ \\
\hline 1 & 1.086 & $0^{\mathrm{a}}$ \\
\hline 60 & 1.113 & $0^{\mathrm{a}}$ \\
\hline 1 & 0.500 & $0^{\mathrm{a}}$ \\
\hline 2 & 0.496 & $0.8^{\mathrm{b}}$ \\
\hline 3 & 0.470 & $6.0^{\mathrm{b}}$ \\
\hline 10 & 0.371 & $25.8^{\mathrm{b}}$ \\
\hline 11 & 0.315 & $37.0^{\mathrm{b}}$ \\
\hline
\end{tabular}




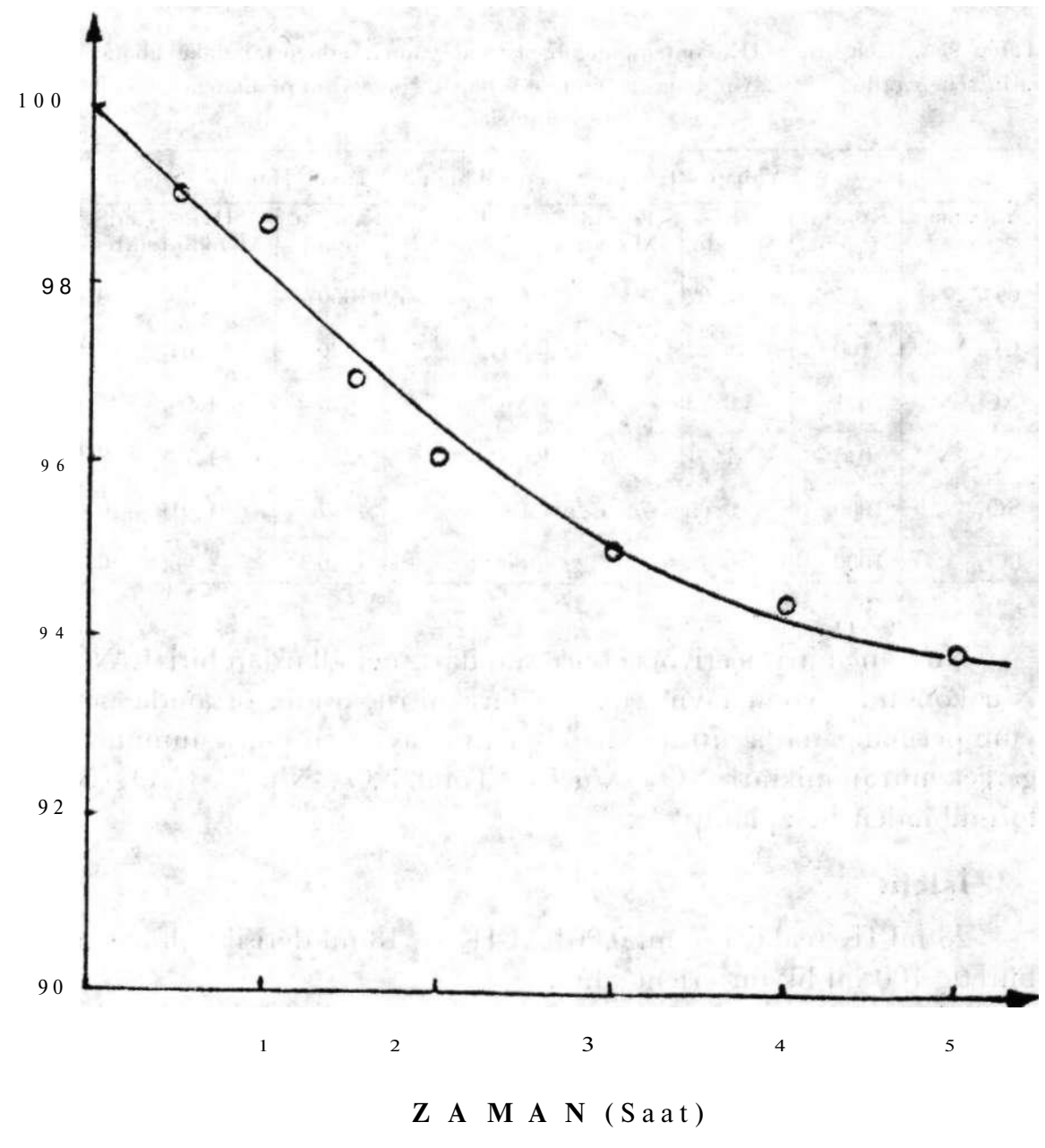

Şekil 5. İK yönteminde ölçüm çözeltisinin absorbansının zamana bağlı olarak değişimi $(0,001 \mathrm{M}$ İK ile $)$

Nitrit iyonunun asidik ortamda potasyum pergamanganatla nitrata yükseltgenmesinin çözeltinin absorpsiyonuna etkisi incelendi.

\section{Geliştirilen Yöntem}

- Reaktif Çözeltisinin Hazırlanması: (Bak. Sayfa 36, No: 3)

- Numunenin Hazırlanması: Numune 100 p pm kadar klorür içeriyorsa katı gümüş sülfatın bir miktar aşırısıyla çöktürülür, bir gece bekletildikten sonra mavi band süzgeç kağıdından süzülür (4). 
Tablo 9. a) Geliştirilen İK yönteminde, b) FdS.a. yönteminde ortamdaki yabancı iyon ların sebep olduğu \% tayin hatası. ${ }^{x}$ Gümüş sülfat, ${ }^{x x}$ potasyum permanganat kullanılan numuneler.

Yabancı İyonun Sebep Olduğu \% Tayin Hatası

\begin{tabular}{|c|c|c|c|c|c|c|c|c|}
\hline $\begin{array}{c}\text { Yabanci } \\
\text { iyon }\end{array}$ & $\begin{array}{c}\text { Konst.u } \\
(\mathrm{ppm})\end{array}$ & $\begin{array}{c}\text { IK } \\
\text { Metodu }\end{array}$ & & $\begin{array}{l}\text { S. a. } \\
\text { todu }\end{array}$ & $\begin{array}{c}\text { Yabanc1 } \\
\text { iyon }\end{array}$ & $\begin{array}{c}\text { Konst.u. } \\
\text { (ppm) }\end{array}$ & $\begin{array}{c}\text { IK } \\
\text { Metodu }\end{array}$ & $\begin{array}{l}\text { FdS. a. } \\
\text { Metodu }\end{array}$ \\
\hline--- & 5 & -32.82 & - & 4.04 & Org. Madde & 1000 & $-\quad 1.29$ & -0.60 \\
\hline $\mathrm{Cl}^{-\mathrm{x}}$ & 100 & $+\quad 5.22$ & - & 18.82 & $\mathrm{NH}_{4}+$ & 420 & +5.01 & - $\quad 18.22$ \\
\hline $\mathrm{NO}_{2}-\mathrm{N}$ & 0.1 & -8.23 & & 0.0 & $\mathrm{Mg}^{++}$ & 625 & -4.99 & -25.80 \\
\hline $\mathrm{NO}_{2}-\mathrm{N}^{x x}$ & 0.5 & $+\quad 1.51$ & - & 8.58 & $\mathrm{Ca}^{++}$ & 250 & $-\quad 4.73$ & -8.97 \\
\hline $\mathrm{SO}_{4}=$ & 1000 & $-\quad 0.68$ & + & 3.29 & $\mathrm{Fe}++$ & 2.7 & +4.91 & +6.82 \\
\hline $\mathrm{PO}_{4}=$ & 1000 & $+\quad 0.79$ & - & 4.22 & $\mathrm{Fe}+++$ & 40 & -4.96 & -6.20 \\
\hline
\end{tabular}

Numune nitrit içeriyorsa önce standart metodlardan biriyle $\mathrm{NO}_{2}$ N'u konsantrasyonu tayin edilir. Sonra nitrit, asidik ortamda potasyum permanganatla nitrata yükseltgenir. Tayinden sonra numunedeki gerçek nitrat miktarı $\mathrm{NO}_{3}-\mathrm{N}^{\prime} \mathrm{u}=\left(\right.$ Total $\left.\mathrm{NO}_{3}-\mathrm{N}^{\prime} \mathrm{u}\right)-\left(\mathrm{NO}_{2}-\mathrm{N}^{\prime} \mathrm{u}\right)$ formülünden hesaplanır (4).

\section{İşlem}

- $23 \mathrm{ml}$ İK reaktifi (5 $\mathrm{ml} 0,001 \mathrm{M}$ İK $+18 \mathrm{ml}$ derişik sülfürik asit) büretle $100 \mathrm{ml}$ lik bir erlene alınır.

- Üzerine büretle $10 \mathrm{ml}$ numune konur ve karıştırılır (Buz banyosu içinde).

- İki dakika beklendikten sonra erlen 10 dakika $100^{\circ} \mathrm{C}$ sicaklıktaki yă

- Yağ banyosundan çıkarılınca buz banyosunda oda sıcaklığına getirilir.

- Çözelti $30 \mathrm{ml}$ kadar suyla seyreltilir (Buz banyosu içinde).

- İki defa $10 \mathrm{ml}$ distile su yardımıla $100 \mathrm{ml}$ lik bir balonjojeye aktarilır, oda sıcaklığına soğuyunca $100 \mathrm{ml}$ ye tamamlanır. Meydana gelen renk $1 / 2$ saat süreyle dayanıklıdır.

- Absorpsiyon ölçümü $612 \mathrm{~nm}$ dalga boyunda $1 \mathrm{~cm}$ 1şık yolu kullanarak yapılır. Tayinlerde her numune serisi için 0,0-1,0 ppm NO3-N'u içeren standart çözeltilerden yararlanarak bir kalibrasyon eğrisi çizilmelidir. 
Eğer numunedeki $\mathrm{NO}_{3}-\mathrm{N}^{\prime} \mathrm{u}$ konsantrasyonu belirtilen miktardan daha yüksekse numune, distile suyla uygun oranda seyreltildikten sonra tekrar işleme tabi tutulur.

\section{SONUÇ VE TARTIŞMA}

Literatür yöntemiyle (8) yapılan çalışmalarda $0,0-2,0$ ppm ve 0,0-8,0 ppm $\mathrm{NO}_{3}-\mathrm{N}^{\prime} \mathrm{u}$ içeren çözeltilerle kalibrasyon eğrisi çizmek mümkün olmadı (Tablo 1). Bunun üzerine deneyde rol oynayan asit konsantrasyonu, 1sıtma zamanı gibi faktörler değiştirilerek deney için optimal şartlar araştırıldı.

9,0-10,6 M sülfürik asit içeren ortamlarda yapılan deneyler tekraredilebilir sonuçlar elde edilmesinde sülfürik asit konsantrasyonunun 1. derecede rol oynamadı̆̆ını gösterdi (Tablo 2).

İK ile nitratın oda sıcaklığında yapılan deneylerde çok düşük oranda reaksiyona girdiği gözlendi. Ortam sıcaklığının suyla sülfürik asitin karışması dolayısıyla takriben $70^{\circ} \mathrm{C}$ ye yükselmesine rağmen 0,0

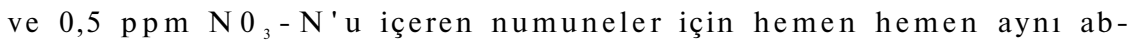
sorbanslar okundu (Tablo 3).

0,001 $M$ ve 0,002 M İK reaktifi ile yapılan deneyler tekraredilebilir sonuçlar elde edilmesinde reaktif konsantrasyonunun rol oynadı̆̆ını gösterdi (Şekil 1).

Soğutma işlemi uygulanan numunelerde daha büyük absorbans değerleri okundu (Tablo 4). Deney esnasında sıcaklık faktörünün kontrol edilmesi gerektiği anlaşıldı.

Aynı miktarda $\mathrm{NO}_{3}-\mathrm{N}^{\prime} \mathrm{u}$ içeren numune serilerinin farklı sıcaklıklarda değişen süreler 1sıtılmaları halinde seriler arası tutarlılı̆̆ın artmadığ 1 gözlendi (Tablo 5). Bu sonuçtan numunelerin $100^{\circ} \mathrm{C} \times 10$ dakika ısıtılmalarının yeterli olduğuna karar verildi.

Ortama sodyum klorür ilave edilmeyen serilerin bazılarında tutarsız sonuçlar elde edildi. Sodyum klorür ilave edilen numune serilerinde ise tekraredilebilir ve düşük sonuçlar elde edildi. Bu da klorürün reaksiyonu katalizlediğini gösterdi (Tablo 6).

Hiç bekletilmeden isıtılan numuneler tutarsız sonuçlar verdiler. 2 dakika bekletildikten sonra isıtılan numuneler tekraredilebilir sonuçlar verdiler. 5 dakika bekletildikten sonra isitilan numunelerde tekraredilebilirlik daha düşük çıktı (Tablo 6). 
Reaktif hazırlama yöntemi değiştirildikten ve sıcaklık değişkem kontrol altına alındıktan sonra sodyum klorür ilave edilmeyen numunelerde ayrı günlerde hazırlanan reaktif çözeltileriyle yapılan 3 seri çalışmada tekraredilebilir sonuçlar alındı. 9 günlük bir zaman dilimi içinde yapılan 14 deneyin ortalaması 0,564 \pm 0,005'tir (Tablo 7). Bu sonuçlardan reaksiyonda katalizör rolü oynayan fakat $\left(\mathrm{NO}_{3}{ }^{-}+3 \mathrm{C}^{-}\right.$ $\left.+4 \mathrm{H}_{3} 0+\rightarrow \mathrm{NOCl}+\mathrm{Cl}_{2}+6 \mathrm{H}_{2} 0\right)$ reaksiyonu uyarınca nitrozil klorür vererek azot kaybına sebep olan (14) sodyum klorürün kullanılmasına ihtiyaç olmadı̆̆ 1 anlaşıldı.

0,001 M İK içeren reaktif çözeltisiyle yapılan çalışmalarda değişik günlerde tekraredilebilir absorbans değerleri okundu. Bu değerlerden yararlanarak lineer regresyonla elde edilen doğrunun denklemi $\mathrm{y}=-0,9223 \mathrm{x}+1,0711$ şeklindedir. Doğrunun korelasyon katsayısı, $r=0,9974$ 'tür (Şekil 2).

(Şekil 3)'te ise FdS. a. metoduyla elde edilen kalibrasyon eğrisi görülmektedir. Bu metodda - İK metodunun aksine- absorbans nitrat konsantrasyonuyla doğru orantılı olarak artmaktadır.

8,0-13,0 $\mathrm{M} \quad \mathrm{H}_{2} \mathrm{SO}_{4}$ asit içeren ortamlarda yapılan tayinlerde 9,6-10,4 $\mathrm{M} \mathrm{H}_{2} \mathrm{SO}_{4}$ bölgesinde daha tutarlı sonuçlar alındı̆̆ (Şekil 4). 10,2 $\mathrm{M} \mathrm{H}_{2} \mathrm{SO}_{4}$ içeren ortamda çalışıldı̆̆ında 0,0-1,0 ppm NO 3-N'u içeren numunelerde okunan absorbanslar spektrofotometrik ölçümlerin \% 2 bağıl hata ile yapılabildiği $0,2-1,0$ değerleri arasında olduğundan çalışmalarda bu asit konsantrasyonu kullanıldı.

Belirli aralıklarla yapılan ölçümlerden ölçüm çözeltisinin absorbansında $1 / 2$ saat içinde $\% 1$, 3 saat içinde \% 5 düşme olduğu gözlendi (Şekil 5).

Önerileri metodla hazırlanan reaktifin incelendiği 60 gün boyunca bozunma göstermediği ve literatürde önerilen reaktif çözeltisinden (8) dayanıklı olduğu gözlendi (Tablo 8).

İK metodu nitrat tayininde kullanilan standart metodlardan FdS. a. metodu $(3,4)$ ile karşılaştırıldı̆̆ında şu sonuçlar alınmaktadır:

İK metodu 0,0-1,0 ppm $\mathrm{N}_{3}-\mathrm{N}^{\prime} \mathrm{u}, \mathrm{FdS}$. a. metodu ise 0,0-2,0 ppm $\mathrm{NO}_{3}-\mathrm{N}^{\prime} \mathrm{u} n \mathrm{a}$ karşıllk gelen absorbans değerleri için LambertBeer kanununa uyan bir doğru verirler.

Hassasiyet İK metodunda 0,018 ppm N0 $0_{3}-\mathrm{N}^{\prime} \mathrm{u}$, FdS.a. meto-

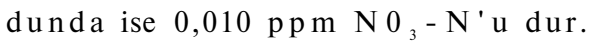


FdS.a. metoduyla tayin kuruluğa uçurma işlemi dolayısıyla 2 saatten fazla zaman aldığından çok hassasiyet gerektirmeyen çalışmalarda İK metodu tercih edilmelidir. Bu metodla tayin süresi takriben 40 dakika tutmaktadir.

Büyük numune serileriyle çalışılması gerektiğinde numune çözeltisinin rengi en aşağ 4 saat dayanıklı olan (15) FdS.a. metodu tercih edilmelidir. Çünkü İK metodunda numune rengi $1 / 2$ saat dayanır.

Suyun komple mineral analizi, yağmur suyunda nitrat tayini gibi numunelerin içerdiği nitrat iyonu konsantrasyonunun düşük olduğu durumlarda her iki metod da kullanılabilir.

İK metoduyla tayinde ortamda hiç klorür olmaması gerekir, FdS.a. yönteminde ise 5 ppm klorür varlığında \% 5 hatayla tayin yapilabilir (Tablo 9).

İK metoduyla 100 p pm klorür gümüş sülfatla çöktürüldügünde \% 5 hatayla tayin yapılabilir. FdS.a. metodunda ise gümüş sülfat kullanıldığında daha kötü sonuçlar elde edilmektedir (Tablo 9).

Nitrit iyonunun her iki tayin metodunda da ortamda bulunmamas1 gerekir.

İK metodunda $0,5 \mathrm{ppm} \mathrm{NO}_{2}-\mathrm{N}^{\prime} \mathrm{u}$ asidik ortamda permanganatla yükseltgenerek tasfiye edilebilmektedir. FdS.a. metodunda ise ayn işlem daha yüksek hataya sebep olmaktadır (Tablo 9).

Sülfat, fosfat, amonyum, magnezyum, kalsiyum, demir (II) ve demir (III) iyonları da İK metodunda FdS.a. metodundan daha az bozucu etki yaparlar (Tablo 9).

Oksidasyona dayanan metodların (İK, Brucin) zaman, sıcaklık asit konsantrasyonu gibi faktörlere bağlı olarak farklı değerler vermeleri her seri için ayrı bir kalibrasyon eğrisi çizilmesini gerektirir.

Reaktif dayanıklılığı açısından İK metodu FdS.a. metoduna üstündür. Fenoldisülfonik asit reaktifi hazırlandıktan 1-2 gün sonra katılaşarak bozunmaktadır. Buna karşılık iki aylık İK reaktif çözeltisi bile tayinlerde tekraredilebilir sonuçlar vermektedir.

\section{L İ T E RA T Ü R}

1- Scorer, R., Nitrogen: A Problem of Decreasing Dilution, New Scientist,62 (4), 182-4 (1974).

2- Höll, K., Water, Walter de Gruyter, Berlin, New York, 68-71 (1972).

3- Taras, M.J., Greenberg, A.E., Hoak, R.D., Rand, M.C., Standard Methods for the Examination of Water and Wastewater, 13 th Ed., APHA, Washington D.C. (1975). 
4- Günay, Y., İçme Suyu ve Pis Sularda Standard Rutin Analiz Yöntemleri Kılavuzu, İller Bankası Yayın No: 24, Ankara (1977).

5- Dhone. S.N., Deshpande, W.M., Statistical Analysis of two Methods used in Nitratenitrogen Determination, İndian J. Environ. Health 28 (1), 8-20 (1986).

6- Türk Su Standartları, Nitrat Analizi, TS 3308/Şubat 1979, TSE, Ankara (1979).

7- Annual Book of ASTM Standards, Test Method For Nitrate Ion in Water, Vol 11.01, D 992-71 (1978), ASTM, Philadelphia (1983).

8- Maly, J., Fadrus, H., Nitrate Determination with İndigo Carmine, J. Am. Water Works Assoc., 67 (7), 395-7 (1975).

9- Marx, Bestimmung der Salpetersaeure in Brunnenwassern, Z. Anal. Chem. 7, 412-14 (1868).

10- Trommsdorff, H., Nachtraege zu den Untersuchungsmethoden für ein Statistik des Wassers, Z- Anal. Chem., 9, 168-76 (1870).

11 - Goppelsroeder, F., Über eine schnell ausführbare und genaue Methode der Bestimmungder Salpetersaeure, sowie über deren Menge in den Trinkwassern Basels, $Z$. Anal. Chem., 9, 1-15 (1870).

12- Mayer, O., Zur Bestimmung der Nitrate im Wasser, £eita:Ar.f. Untersuchung der Lebensmittel, 66, 193-200 (1933).

13- Ungar, J., Determination of Nitrates in aqueous Solution, J. Appl. Chem. 6, 245-8 (1956).

14- Wagner, R., Neue Aspekte zur Stickstofffanalytik in der Wasserchemie, vom Wasser, 36,263-318 (1969).

15- Sayato. Y., Ando, M., Spectrophotometrical Property on Phenoldisulphonic Acid Method for the Determination of Nitrate Nitrogen, Eisei Kagaku,16 (6), 311-17 (1970). 